\title{
A AÇÃO TERRITORIAL DOS SINDICATOS NO LIMAR DO SÉCULO XX NO BRASIL
}

\author{
Amir El Hakim de Paula*
}

\section{RESUMO:}

Este artigo tem como objetivo discutir as territorialidades dos sindicatos no Brasil nas primeiras décadas do século XX. Nesse sentido, procuraremos demonstrar essas ações territoriais em dois períodos: o primeiro, até o início da década de 1920, quando havia grande pluralidade sindical e pouca participação do Estado nas relações entre o capital e o trabalho, e, após a Revolução de 1930, quando o Estado iniciou uma intervenção na organização interna dessas entidades e, consequentemente, em suas ações territoriais.

\section{PALAVRAS-CHAVE:}

Geografia; Território; Territorialidade; Sindicatos; Brasil

\section{ABSTRACT:}

This article discusses the trade unions' territorialities in Brazil in the first decades of the $20^{\text {th }}$ century. Their territorial actions are divided in two periods: the first ends at the beginning of the 1920s, when there was great trade union plurality and little State participation in the capital work relations. The second period begins after the 1930 Revolution, when the State started intervening in the trade unions' organization and, therefore, in their territorial actions.

\section{KEYWORDS:}

Geography; Territory; Territoriality; Trade Unions; Brazil

\section{Introdução}

Os estudos sobre o sindicalismo brasileiro tiveram um aumento qualitativo nos últimos anos na Geografia, surgindo inúmeras dissertações e teses sobre a estrutura e funcionamento dos sindicatos rurais no país.

Dentre essas pesquisas, poderíamos citar a tese de doutoramento de Thomaz (1996) sobre a territorialidade da organização sindical do setor sucroalcooleiro, bem como os trabalhos produzidos no âmbito do CEGET (Centro de Estudos da Geografia do Trabalho).

Entretanto, poucos foram os geógrafos que procuraram entender a organização dos trabalhadores urbanos. Ainda na década de 1980,
"[...] no campo da Geografia, esses estudos são praticamente inexistentes. O operariado, enquanto classe e sujeito-objeto da história merece vaga referência, e é confundido no tema genérico da população." (MOREIRA, 1985, p.21)

O nosso interesse em um aprofundamento maior de estudo sobre o sindicalismo brasileiro surgiu durante o bacharelado em Geografia, quando realizamos uma pesquisa acerca das origens do movimento operário no Brasil, como trabalho de conclusão de curso.

Desde então, nossas pesquisas se remetem a esse temário (operariado no Brasil), seja na análise macroespacial como no trabalho de conclusão de curso, seja numa pesquisa mais

*Aluno de doutorado do programa de pós-graduação em Geografia Humana da Universidade de São Paulo. 
delimitada espaço-temporalmente, como em nossa dissertação de mestrado sobre o operário em São Paulo no início do século XX.

Nesse artigo, apresentaremos alguns dados iniciais de nossa pesquisa de doutorado em curso, cujo objetivo é entender as territorialidades sindicais no país, do início do século XX até a década de 1930. Ou seja, compreender como os sindicatos se organizavam no território brasileiro no limiar do século $X X$ e como as mudanças ocorridas com a chegada ao poder de Getúlio Vargas em 1930, transformou completamente essa estrutura sindical.

Dentre as mudanças ocorridas no início da década de 1930, interessam-nos principalmente aquelas que se referem à ação do Estado, alterando as formas de relacionamento existentes até então entre as entidades sindicais.

Compartilhamos da hipótese de que a Revolução de 1930, tendo como base uma maior centralização do poder $^{1}$, procurou limitar a escala de ação dos sindicatos, "adequando-os" a um modelo único oficial.

Essa intervenção na forma de organização dessas entidades determinou a fragmentação de suas lutas, separando, por exemplo, sindicatos de uma mesma categoria pela sua base territorial. Ou seja, inibiu um maior contato entre as agremiações das áreas menos industrializadas com seus congêneres do Centro Sul do país.

A fim de compreender melhor essas mudanças, definimos metodologicamente um recuo histórico antes de 1930 e também a discussão conceitual sobre território e territorialidade.

\section{Fundamentos.}

\section{Território e Territorialidade: Principais}

Na história da ciência, os estudos sobre território e territorialidade foram objetos de preocupação de vastas áreas do conhecimento, como a botânica e a zoologia, por meio dos trabalhos de naturalistas do século XVIII ou mesmo pela Etologia de Auguste Comte, para citar os principais. (MORAES, 1984, p. 91)
O temário ganhou um significado importante para a ciência geográfica no final do século XIX e início do século $X X$, por meio dos trabalhos de Ratzel, principalmente na sua obra Antropogeografia. (MORAES, 1984, p.91). Sua concepção prioriza o papel do território (e sua organização) pelo ponto de vista do Estado, compreendendo qualquer outra manifestação no território, que não a estatal, como uma excepcionalidade, ou seja, uma ação "extraterritorial".

Muito presente na Geografia (principalmente na Geografia Política), essa concepção de território teve sempre um papel destacado entre os intelectuais brasileiros do início do século XX, como Backheuser, Elysio de Carvalho e Delgado de Carvalho, claramente influenciados pelas concepções de Ratzel.

Entretanto, mais recentemente alguns geógrafos procuraram teorizar sobre essa questão, incluindo em suas pesquisas algumas visões advindas de outras ciências (como por exemplo, a antropologia), gerando críticas daqueles que não concordam com tal apropriação².

Dentre os autores que buscaram outras formas de entendimento sobre território, poder e territorialidade encontramos Claude Raffestin. Para o geógrafo suíço o território "[...] é o resultado de uma ação conduzida por um ator sintagmático (ator que realiza um programa) em qualquer nível)"(RAFFESTIN, 1993, p.143).

Baseado largamente nas concepções foucaultianas ${ }^{3}$ de poder, o autor diverge da ideia que admite o Estado como única fonte dotada de ação no território, como fica evidenciado nas suas críticas à chamada Geografia Política clássica, ao afirmar que "[...] em vez de se interessar por qualquer organização dotada de poder político suscetível de se inscrever no espaço, a Geografia Política só vive, e em conseqüência, só fez a análise de uma forma de organização: a do Estado." (RAFFESTIN, 1993, p.28)

As abordagens de Raffestin sobre a relação território e poder, permitem produzir "[...] 
uma Geografia Política que dê conta das formas novas e complexas de exercícios de poder, em sua relação com o espaço, que propriamente com o Estado em si". (COSTA, 1988, p.24)

A partir dessas teorizações, o monopólio do poder sobre o território não se fixa apenas e tão somente na ação estatal, sendo que outros agentes sociais, como os sindicatos, por exemplo, aparecem como organismos de grande atuação no território, questionando em alguns casos, mesmo que simbolicamente, a estrutura dominante determinada pelo poder central.

Sendo assim, as ações dessas entidades não podem ser ocultadas, visto que muito embora a relação poder-Estado-território seja a mais evidente, alguns

"[...] mecanismos políticos se desenvolvem através da atuação da sociedade civil em sua relação com as formas institucionalizadas do poder.[...]Tais mecanismos, aqueles que interferem nessa relação [poder-território] desenvolvem-se através das formas e organizações já conhecidas como partidos, sindicatos, entidades, etc" (COSTA, 1988, p.24).

Outro autor importante nessa discussão metodológica é Rogério Haesbaert (2004), que aponta pelo menos três concepções básicas de território: a política ou jurídico-política, a mais difundida, na qual o território é visto como um espaço delimitado e controlado, através do qual se exerce um determinado poder, na maioria das vezes - mas não exclusivamente - relacionado ao poder político do Estado; a cultural ou simbólica, na qual o território é visto, sobretudo, como o produto da apropriação/valorização de um grupo em relação ao seu espaço vivido; e a econômica, aquela que enfatiza a dimensão espacial das relações econômicas.

Desta forma, o autor necessariamente multiplica as possibilidades de entendimento acerca da relação poder-Estado-território, ao considerar outras formas de análise e não apenas a político-jurídica.

Ao ampliar as análises sobre o território e seus agentes, Haesbaert (2004) discute também as diversas formas de territorialidades. Baseandose nas análises de Sack (1980), o autor mostra que a territorialidade não deixa de ser uma estratégia de controle, visto que é a partir dessa ação no território que se pode controlar recursos ou mesmo impor novas relações.

Para o autor, o conceito de territorialidade deve ser usado também

"[...] para enfatizar as questões de ordem simbólico-cultural. Territorialidade, além da acepção genérica ou sentido lato, onde é vista como a simples qualidade de seu território, é muitas vezes concebida em um sentido estrito como a dimensão simbólica do território" (HAESBAERT, 2004, p. 74).

Entendemos a partir dessas teorizações que o conceito de territorialidade pode ajudarnos a compreender as práticas dos sindicatos no território antes de 1930, e também quais foram as consequências das intervenções estatais nessas ações territoriais, quando da chegada ao poder de Getúlio Vargas.

O território não pode ser entendido como área de atuação de um único agente (o Estado), pois outros organismos, entre eles os sindicatos, também atuam nele.

Partindo dessa premissa, trabalharemos adiante com as diversas formas de territorialidades impressas pelo movimento sindical no território nacional, e como o Estado, a partir da Revolução de 1930, interferiu nessa dinâmica.

\section{As territorialidades do movimento sindical no Brasil no início do século $\mathrm{XX}$ aos anos de 1930}

Antes de analisarmos as ações territoriais dos sindicatos, buscaremos entender o processo de industrialização que acontece em fins do século XIX e início do século XX.

Estudado por diversos autores, a compreensão do processo de industrialização suscitou grandes debates. Dean (1971) defende a tese de que esse processo ocorreu, 
principalmente, com a entrada de capitais estrangeiros que chegavam às casas importadoras que trabalhavam com bens de produção, e que posteriormente foram aplicados na indústria. Mello (1982) declara a grande importância dos capitais advindos da economia cafeeira.

Com uma perspectiva diferente, Martins (1986) destaca que não foi necessariamente o café que propiciou o surgimento de uma economia monetária, pois desde o século XVIII algum tipo de economia exportadora existia em São Paulo, e por isso conclui que"o aparecimento da indústria está vinculado a um complexo de relações e produtos que não pode ser reduzido ao binômio café-indústria" (MARTINS, 1986, p. 106). ${ }^{4}$

Concomitantemente à industrialização, houve a formação da classe operária, composta em sua maioria por imigrantes, principalmente europeus, que ao país vinham em grande número ${ }^{5}$.

Sem quase nenhum amparo social do Estado e vivendo em uma condição de grande penúria, esses trabalhadores começaram a se organizar, primeiro em sociedades de apoio mútuo e depois em sindicatos.

Grande parte dessas organizações sindicais, em sua maioria anarcossindicalistas, sobrevivia em um ambiente no qual havia pouca intervenção estatal (quase sempre a intervenção se resumia à repressão), dependendo das cotizações de seus filiados para sobreviverem, o que possibilitava que fossem independentes, mas também efêmeras.

Embora fossem anarquistas, ou seja, defendessem a destruição do Estado e a autogestão operária, os anarcossindicalistas entendiam que a educação política ou mesmo a ação direta não poderia estar desvinculada da organização dos trabalhadores em órgãos de resistência, visto que essas entidades seriam os veículos para a conquista de uma sociedade mais justa.

Desta forma, a organização interna de um sindicato anarcossindicalista, espelharia o modelo de organização social desejado pela classe operária numa possível sociedade futura, no qual "na federação livre, grupos autônomos de trabalhadores podem e sabem melhor que outros, organizar diretamente a produção e o consumo, ou todas as funções sociais úteis e necessárias" (SFERRA, 1987, p. 19).

Para os anarcossindicalistas, a greve, principalmente a greve geral, era um instrumento de luta que possibilitava conquistas parciais à classe trabalhadora, como aumento de salários, diminuição da jornada de trabalho, etc, mas também era um aprendizado na forma de como a classe deveria se organizar.

Tais ações seriam pautadas em um relacionamento autônomo entre as entidades de classe, de forma

"que a união da categoria evolua para a união da classe trabalhadora como um todo, formando um exército compacto e disciplinado para o evento final, que é a transformação da sociedade capitalista em uma nova sociedade, na qual tudo seja propriedade dos que produzem: os trabalhadores" (SFERRA, 1987, p. 27).

Ainda que o movimento sindical, em larga medida, estivesse concentrado na região sudeste, principalmente nos estados do Rio de Janeiro e de São Paulo, até 1920 ocorreram três congressos nacionais.

O I Congresso Operário Brasileiro realizouse no Rio de Janeiro, de 15 a 22 de abril de 1906, e contou com a participação de representantes de vários estados, como a Federação Operária de São Paulo, a Federação Socialista Baiana e o Centro Protetor dos Operários de Pernambuco.

Nesse encontro foram afirmados alguns princípios anarcossindicalistas, tais como a autogestão, o federalismo, a autonomia nas diversas esferas, o enfrentamento de classes e a necessidade de criação de sindicatos de ofícios vários, quando a categoria não conseguisse ainda ter uma organização independente.

A maior concentração de entidades estava no antigo Distrito Federal (atual cidade do Rio de 
Janeiro), com 21 associações, o que revela "a estreita correlação entre a concentração da atividade industrial e a aglutinação da mão-deobra assalariada" (BERNARDO, 1982, p. 43).

Como resultado desse congresso foi lançado em 1908 o jornal "A Voz do Trabalhador", periódico de grande importância para a articulação do movimento operário nacional, bem como formada a Confederação Operária Brasileira, claramente influenciada pela CGT francesa. ${ }^{6}$

O II Congresso Operário Brasileiro ocorreu entre 8 e 13 de setembro de 1913, no Rio de Janeiro, e contou com a participação de duas federações estaduais (Rio Grande do Sul e Alagoas), mas também representantes de sindicatos de São Paulo, Amazonas, Rio e Minas Gerais.

Nesse congresso se reafirmaram os postulados anarcossindicalistas e, ao contrário do $1^{0}$ congresso, já se via uma maior organização da classe operária, fato esse demonstrado pela grande atividade sindical ocorrida entre os dois congressos.

Isso aconteceu devido à predominância de intensas greves no período que vai do $1^{\circ}$ ao 20 Congresso, bem como a luta dos trabalhadores em se oporem à lei Adolfo Gordo ${ }^{7}$, que determinava a expulsão de militantes operários imigrantes.

O III Congresso Operário Brasileiro realizou-se entre 23 e 30 de abril de 1920, no Rio de Janeiro, contando com a participação de 150 delegados, representando cerca de 75 associações sindicais de vários estados como Amazonas, Pará, Paraná, São Paulo e Rio de Janeiro.

Esses três congressos demonstram uma grande presença sindical no território nacional, sindicatos sendo encontrados em regiões afastadas do grande centro industrial, como nos estados do Amazonas e do Pará, por exemplo.

Nesse período inicial (até meados da década de 1920), a principal intervenção do Estado nas relações entre o Capital e o Trabalho se dava na repressão ao movimento operário por meio das investiduras policiais. Entretanto surgiram algumas leis trabalhistas.

Uma importante lei do período foi o decreto no 1637, de 05 de Janeiro de 1907. Um dos artigos centrais desse decreto versava sobre a questão territorial. Dizia o artigo:

"Os sindicatos terão a faculdade de se federar em uniões ou sindicatos centrais, sem limitação de circunscrições territoriais (grifo nosso). As federações terão personalidade civil separada e gozarão dos mesmos direitos e vantagens dos sindicatos isolados" (Decreto no 1637 apud MORAES FILHO, 1978, p. 186).

Ao analisarmos esse decreto percebemos que o Estado não interferiria de forma sistemática nas relações entre os sindicatos, fossem essas municipais, estaduais ou nacionais, propiciando a emergência de diversas relações intersindicais, algumas delas discutidas posteriormente.

Muito embora a lei permitisse inúmeras relações interterritoriais entre os sindicatos, possuindo forte influência federalista ${ }^{8}$, não podemos afirmar categoricamente que a lei incentivou as inúmeras territorialidades sindicais existentes, visto que, em várias situações essas relações não levavam em consideração, por exemplo, a divisão político-administrativa vigente.

As múltiplas territorialidades sindicais desse período ocorreram, para nós, muito mais pela predominância das ideias anarcossindicalistas nos sindicatos, do que propriamente pelo poder da lei.

A presença dessa ideologia nessas entidades propiciava uma organização horizontal, federalista e largamente baseada em laços de afinidades.

Um movimento operário fundamentado nesses princípios possibilitava a existência de redes de solidariedade entre os trabalhadores, e dinâmicas territoriais baseadas, única e exclusivamente, em suas necessidades. 
Para os sindicatos de orientação anarcossindicalista

\begin{abstract}
"organizar é levar a classe trabalhadora a se associar em ligas operárias, uniões de ofícios, associações e sindicatos, que são o centro de livre discussão e educação no qual o proletariado aprende que sua emancipação econômica será obtida por meio da união da classe, mas não para reivindicar e mendigar reformas no sistema de trabalho, na espera que estes façam leis e melhorem sua situação. Os trabalhadores, unidos nessas associações, discutem e formulam propostas com o intuito de solidários, tomar uma ação conjunta e impor seus interesses por meio da resistência e pressão direta constante sobre os donos do capital"(SFERRA, 1987,p. 63).
\end{abstract}

Essa maciça presença libertária nos meios sindicais, junto a uma pluralidade de entidades, permitiu várias articulações entre os sindicatos no país.

E mesmo tendo como obstáculo a extensão territorial do país e as precárias condições de comunicação (visto que até 1922 o principal meio de comunicação eram os telégrafos), quando ocorria um movimento de grande expressividade nos meios operários, sua ressonância atingia regiões afastadas do eixo RioSão Paulo.

Foi o que aconteceu na Greve Geral de 1917 em São Paulo. Embora surgisse limitada a uma categoria (têxteis), o movimento paredista logo se alastrou pela cidade, tendo ocorrido greves de solidariedade ao movimento em várias localidades do Estado (Campinas, Sorocaba, Jundiaí), no Rio de Janeiro, em Curitiba e, em áreas mais afastadas, foram notadas manifestações de solidariedade, como Recife, Manaus e Belém. (LOPREATO, 2000)

Para Moreira (1985), as greves gerais que ocorreram no período de 1917 a 1920, demonstram certa maturidade do movimento operário brasileiro, visto que já se organiza nacionalmente e sob uma única orientação, acompanhando dessa forma a dinâmica da economia fabril que, outrora regionalizada, aos poucos ia se tornando nacional ${ }^{9}$ (MOREIRA, 1985, p.80).

Desta forma, percebemos que mesmo com todas as dificuldades na organização dos sindicatos, os operários estavam atentos aos movimentos que ocorriam no país, quase sempre realizando manifestações de apoio.

A estruturação do funcionamento da Confederação Operária Brasileira e a necessidade de superação dos obstáculos criados pela extensão territorial que, de alguma forma, dificultava a organização das entidades sindicais distantes dos grandes centros, propiciaram a presença de diversas relações interterritoriais entre os sindicatos.

Até o início dos anos de 1930 havia uma grande pluralidade sindical, ocorrendo às vezes presença de duas entidades representando a mesma categoria, em uma única base territorial. Quando isso ocorria, não era incomum as entidades procurarem um acordo. É o que vemos no caso dos padeiros do Rio de Janeiro

\section{"Sindicato dos Operários Panificadores}

Em assembléia jeral realizada no dia 8 do corrente, para rezolver sobre a regulamentação do trabalho a seco, ficou rezolvido por unanimidade fixar o número em $2 \$$ diários, para a manutenção de todos os trabalhadores em padarias, dependendo somente da aprovação da sua co-irmã, a liga federal dos empregados em padarias"( $A$ VOZ DO TRABALHADOR, 15/02/1914, p.04).

Um fato também interessante de se analisar ocorreu com a categoria de pedreiros e estucadores. Vejamos o caso.

\section{"Brazil Operário \\ Estado do Rio}

Niterói - O sindicato de pedreiros e estucadores de Niterói comunica-nos que tem havido uma grande ajitação naquela cidade, e que muitos operários desta capital estão ali trabalhando sem pertencerem aquele sindicato ou ao Sindicato dos estucadores do Rio. 
Informa-nos ainda que, para poderem trabalhar é precizo que esses operários aprezentem o recibo de sócio quite do Sindicato do Rio, ou cazo não estejam ainda associados, filiaremse a qualquer um dos sindicatos desta capital ou de Niterói"(A VOZ DO TRABALHADOR, 15/ 12/1913, p.03).

Nessa reportagem, o jornal aponta, em primeiro lugar, a força do sindicato de estucadores e pedreiros, pois obrigava os donos de empresa a só aceitarem trabalhadores sindicalizados e quites com a contribuição.

Posteriormente o jornal aponta que os sindicatos de pedreiros do Rio e de Niterói propunham que os trabalhadores se sindicalizassem, independente da cidade em que trabalhassem, ou seja, o mais importante era a filiação ao sindicato, ocorrendo uma solidariedade entre ambos, que não disputavam o mesmo trabalhador e sua contribuição.

A análise dos documentos operários permitiu observar, no que tange às relações territoriais dos sindicatos, a presença de uma extensa gama de possibilidades, baseadas livremente em suas necessidades mais urgentes.

Nesse sentido, se no primeiro caso houve a possibilidade de duas representantes da mesma categoria, na mesma cidade, chegarem a um acordo, vemos no segundo caso que, ás vezes, operários se filiavam aos sindicatos não ligados estritamente à base territorial que a indústria ocupava.

Para os sindicatos dos estucadores era mais importante ter o trabalhador sindicalizado, independente da base territorial a que ele estaria vinculado pelo trabalho.

Como forma de facilitar a organização do 30 Congresso Operário Brasileiro em 1920, os sindicalistas resolveram dividir o país em 5 regiões, nas quais os sindicatos estariam subordinados a um grande centro industrial. Essa divisão levava em consideração aspectos locacionais mas também socioeconômicos.

O extremo norte, com sede em Belém, compreendia os estados de Amazonas, Acre,
Maranhão, Ceará e Piauí; o norte, com sede em Recife, compreendia os estados de Pernambuco, Paraíba, Rio Grande do Norte, Alagoas, Sergipe e Bahia; o centro, com sede no Rio, compreendia o antigo Distrito Federal, o estado do Rio, e Minas Gerais (excetuando o sul e o triângulo mineiro); o sul, com sede em São Paulo, compreendia os estados de São Paulo, Goiás, Mato Grosso, o Triângulo Mineiro e o Sul de Minas e por fim, o extremo sul, com sede em Porto Alegre, compreendia os Estados do Paraná, Santa Catarina e o Rio Grande do Sul ${ }^{10}$.

O estado de Minas Gerais, devido a sua extensão e particularidades econômicas, foi dividido em duas grandes áreas pelos sindicalistas, tendo em vista a organização do $3^{\circ}$ Congresso Operário em 1920. O sul de Minas Gerais (região que compreende a cidade de Poços de Caldas) e o triângulo mineiro (compreendendo as cidades de Uberaba e Uberlândia) foram desmembrados e agrupados na seção sul, capitaneada por São Paulo.

Esse desmembramento do Estado de Minas Gerais em três departamentos (Minas Gerais, Triângulo Mineiro e Sul), sendo os dois últimos liderados pela cidade de São Paulo, pode demonstrar a clara influência econômica da capital paulista sobre essas regiões mineiras.

Interessante anotar que essa divisão geográfica ou regionalização do espaço ocorria desde a década de 1910 e determinava os vínculos entre os sindicatos e as federações operárias.

Um dos principais exemplos foi a Liga Operária de Poços de Caldas, nas Minas Gerais, que optou por se filiar à Federação Operária de São Paulo desde a sua fundação, ocorrida em 1914 (DIAS, 1977, p.286).

A liga operária dessa cidade mineira então estreitava laços com uma federação operária muito mais organizada e consequentemente mais ativa.

Essa relação ocorria graças à proximidade territorial, mas também à força da indústria paulista na região mineira, 
levando alguns sindicatos a se organizarem conforme essa dinâmica.

Outro caso de territorialidade que não se limitava à divisão político-administrativa, ocorreu em 1920, no Pará, quando a Aliança dos Empregados em Comércio e Indústria, se filiou à sua congênere do Rio de Janeiro. Diz a base de acordos da entidade paraense:

"Art. 50 - A Aliança será filiada à Federação dos Trabalhadores do Rio de Janeiro e à Confederação Operária Brasileira sempre que estejam baseadas no acordo com os fins da aliança e mantenham a mesma orientação de que trata e mantenham a mesma orientação de que trata o art. 30 destas bases". afirma:

E explicando os motivos de tal filiação

\begin{abstract}
"[...] [os trabalhadores] resolveram a fundação da Aliança dos Empregados no Comércio e Indústria do Pará a qual será composta de empregados do comércio e casas industriais e será filiada á Aliança dos Empregados no Comércio e Indústria do Rio de Janeiro, afim de com esta e outras associações do paiz fundar a Federação Nacional dos Empregados do Comércio e Indústria". ${ }^{11}$
\end{abstract}

Com a revolução de 1930, o governo que assumiu impôs uma intervenção mais forte do Estado nas relações entre o trabalho e o capital. Foi criado em 26 de Novembro de 1930, por meio do decreto 19.433 , o Ministério do Trabalho, Indústria e Comércio, que teria a incumbência de, nas palavras de Getúlio Vargas, "[...] substituir a luta de classes negativista e estéril, pelo conceito orgânico e justo de colaboração entre as classes" (Apud BERNARDO, 1982 , p. 84).

O Estado passou a ter um controle sobre a sociedade, e desta forma, os sindicatos, graças á sua pluralidade e mobilidade existentes, surgiam como elementos perturbadores dessa nova ordem.

Esse controle, que foi iniciado logo após a revolução de 1930, tinha o território como um dos principais sustentáculos do poder e, por isso, mereceria um melhor ordenamento, já que era gerido, até então, de forma pouco centralizadora.

\section{Como afirma PENHA (1993)}

"[...] o território, neste particular, adquiriu uma discussão política bastante significativa. A intenção de Vargas de tornar o Estado de dimensões tão vastas quanto o país, tinha o sentido de redimensionar espacialmente o alcance das políticas governamentais nas quais o controle da população (mercado/ nação) e o território (país) eram condicionante fundamental não só para a consecução destas políticas, como também para a própria consolidação do Estado Nacional" (PENHA, 1993, p. 63).

Concomitantemente a essa intervenção, ocorreu também um cerceamento das ações territoriais dos sindicatos existentes (seja de empresários, mas principalmente de trabalhadores) por meio de uma lei que criava a unicidade sindical no país.

Em 1931, o Estado promulga o decreto no 19.770 que extinguia a pluralidade sindical e institui a obrigatoriedade de um único sindicato por categoria e base territorial.

Essa política estatal modificou completamente a forma de organização interna e territorial dessas agremiações. As entidades sindicais foram obrigadas a serem 'reconhecidas' pelo Ministério do Trabalho.

Tal política procurou claramente controlar quaisquer ações territoriais determinadas por setores da sociedade civil, independente de serem ou não divergentes da estrutura oficial.

Nas palavras de Oliveira Vianna (1951), principal técnico do Ministério do Trabalho na década de 1930, a intervenção foi necessária para "de um lado, a eliminação do espírito de localismo e de outro, a eliminação do espírito de internacionalismo". E completa o raciocínio, afirmando que: 
"[...] do Amazonas ao Rio Grande por todo o Brasil, os nossos homens do trabalho, individualmente ou agrupados nos seus sindicatos voltam, na sua unanimidade, o seu pensamento para aqui, para o centro político da Nação, como agulhas imantadas atraídas por um pólo magnético"(VIANNA, 1951, p. 90).

O discurso oficial, representado aqui pelas palavras de O.Vianna, demonstra a clara intenção do governo revolucionário de 1930 de centralizar e direcionar as ações territoriais dos sindicatos.

O objetivo dessa ação estatal foi aparelhar internamente os sindicatos, mas também delimitar a sua área de influência, ou seja, fragmentar as ações dos sindicatos no território nacional, obstando, por exemplo, a formação de uma rede nacional difusa, porém organizada. permitiu

O processo de controle dos sindicatos

"[...] a criação de um conjunto muito grande de sindicatos por categorias profissionais e divididos territorialmente pelos limites administrativos municipais sem necessariamente estar vinculado às manifestações da dinâmica do trabalho, ou á luta dos trabalhadores propriamente" (CARVALHAL, 2004, p. 23).

Com o Decreto no 24.694, de julho de 1934, as relações entre os sindicatos de trabalhadores ficaram cada vez mais restritas. Em que pese eles poderem formar uniões municipais ou mesmo nacionais, esses sindicatos só poderiam efetivar essa união, desde que possuíssem sindicatos na escala local, diferentemente dos sindicatos dos empregadores que poderiam se unir independentemente de sua organização na escala local. ${ }^{12}$

Desta forma, enquanto aos empresários era facultada a opção de se reunirem nacionalmente, sem necessariamente terem sindicatos locais, aos trabalhadores essa possibilidade era negada, enfraquecendo sua organização e concomitantemente suas lutas. ${ }^{13}$

E quando algum sindicato, mesmo que reconhecidamente não sendo de matriz revolucionária, procurava ampliar sua área territorial de ação, essa proposta era negada pelo Ministério do Trabalho.

É o que vemos no parecer do Ministério do Trabalho, publicado na Revista do Trabalho.

"Um syndicato local não pode estender sua jurisdicção a outra localidade em que haja syndicato da mesma profissão devidamente reconhecido.

I-Não há margem legal de amparo a reclamação da Associação de Operários de América Fabril. Trata-se de um syndicato local, com sede no Districto Federal, que pretende extender o seu raio de actividade a municípios de outros Estados, ou seja, até Pau Grande, Districto do Município de Magé, Estado do Rio de Janeiro" (REVISTA DO TRABALHO, 1937).

Esse caso demonstra a atuação do Estado na ação territorial dos sindicatos proibindo uma ampliação da área de influência.

O enquadramento do sindicato possibilitou mais do que um simples controle. Ele promoveu uma maior fragmentação da classe operária e dificultou a organização territorial dessas entidades.

Enquanto na República Velha alguns sindicatos unificavam-se com seus congêneres mais organizados, como forma de fortalecer seus laços na luta contra o capital ${ }^{14}$, a partir de 1930 , essas ações seriam dificultadas, estimulando-se, com a lei de sindicalização, o surgimento de sindicatos sem qualquer expressividade, compostos por uma burocracia desinteressada pelas demandas de seus associados.

Para nós, a ação estatal impôs ao operariado uma fragmentação territorial, já que circunscreveu esse movimento à rígida divisão administrativa oficial, dinâmica essa que não seria necessariamente a seguida pelo capital.

Nesse sentido, as ações do Estado promovem a pulverização das lutas dos trabalhadores e transformam os sindicatos em organismos assistencialistas. Como afirma Moreira (1985) 


\begin{abstract}
"Dissolvendo a regra básica anarcossindicalista de deixar a forma de organização sindical entregue às determinações das próprias necessidades da movimentação operária o Estado cria o sindicato único, padronizado, sendo características dessa padronização o particularismo, o paralelismo e o verticalismo. [...] O critério da correlação categoria-território destina-se à desagregação da unidade das ações do operariado sobre a base da reiteração da divisão técnica do trabalho capitalista, submetendo-as, na segregação categorialterritorial, à tutela ministerial" (MOREIRA, 1985, p. 108).
\end{abstract}

Ao delimitar a área de atuação do sindicato quase sempre circunscrita à divisão geográfica oficial, o Estado conseguiu diminuir as relações intermunicipais e inter-regionais dessas entidades, controlando os sindicatos mais fortes e obstando o fortalecimento das categorias que estavam em fase de amadurecimento e que necessitavam unirem-se aos seus companheiros de luta.

Mais ainda, trouxe para o interior da classe operária uma maior fragmentação territorial e de categorias, o que a médio prazo dificultou quaisquer possibilidades de formação de amplas uniões nacionais (como a formação de uma central) ou mesmo de diversas categorias em busca de um resultado comum (como a que ocorreu na Greve Geral de 1917).

Essa ação estatal, ao interferir na organização interna e de relações dos sindicatos, contribuiu para o surgimento de uma organização sindical mais enfraquecida, totalmente dependente e de limitada ação territorial.

\section{Notas}

${ }^{1}$ Como aponta Costa (1988) "O regime político imposto ao país pelos golpistas é marcadamente autoritário e centralizador". (COSTA, 1988, p.44)

${ }^{2}$ Para a Antropologia, território é o espaço pelo qual um grupo étnico tem acesso aos recursos que tornam possível a sua reprodução material e espiritual. Para uma análise crítica dessa conceituação ver em : Moraes, Antonio Carlos Robert . Geografia, Capitalismo e Meio Ambiente, p.45.

${ }^{3} \mathrm{O}$ poder para Foucault não pode ser localizado em um único ponto, como o Estado, por exemplo. Ele é relacional, dinâmico, mantém ou destrói grandes esquemas de dominação, numa grande correlação de forças. Ver mais em: Foucault, Michel . Microfísica do Poder. Rio de Janeiro: Graal, 1995.

${ }^{4}$ Uma melhor compreensão de algumas das várias concepções sobre o processo de industrialização no início do século XX, está em Suzigan, Wilson. Indústria Brasileira: Origem e Desenvolvimento. São Paulo: Editora Brasiliense, 1986.

${ }^{5}$ Dados apontam que entre 1871 e 1920 entraram no país 3.390.000 pessoas, conforme MARAM, Leslie Sheldon. Anarquistas, Imigrantes e o
Movimento Operário no Brasil 1890-1920, p.13. No caso do Estado de São Paulo, em 1920, 70\% do operariado e $64,2 \%$ dos donos de indústrias eram imigrantes. Para mais detalhes sobre a composição imigrante na indústria ver: BERNARDO, Antonio Carlos. Tutela e Autonomia Sindical, p. 19.

6 A CGT- Confederation Generale du Travail - é uma organização sindical nascida em 1895 e que a partir de seu congresso de 1906 ( no qual adotou a Carta de Amiens) tornou-se adepta de várias proposições anarquistas, como a ação direta, o apoliticismo, o federalismo, funcionando como órgão de resistência dos operários na luta contra o Capital e o Estado. Na década de 1920, cisões internas fizeram a Confederação mudar suas proposições ácratas, tornando-se majoritariamente comunista.

7 A Lei Adolfo Gordo, de 07 de janeiro de 1907, previa a expulsão de estrangeiros que comprometessem a ordem nacional, ao participarem de greves e manifestações.

8 Moraes Filho (1978) aponta que essa lei foi largamente baseada na legislação sindical 
francesa de 1884, a qual permitia grande pluralidade sindical.

9 "Assim, quanto mais o espaço molecular se unifica e se torna nacional, mais se unifica e se torna nacional o operariado. [...] Como que em claro enunciado dessa configuração escalar, no período 1917-1920, o movimento operário paralisa nacionalmente o trabalho em greves que vão se sucedendo de um para outro lugar, sob uma só orientação e programa, do Rio Grande do Sul ao Pará, em "greves gerais" por todo o país (RS, SP, RJ, BA, PE, PA), anunciando sua maturidade como sujeito histórico" (MOREIRA, 1985, p. 80).

${ }^{10}$ Conforme Boletim da Comissão Executiva do 30 Congresso Operário, p.4.

${ }^{11}$ Trechos extraídos do jornal A Voz do Trabalhador - Pará- n०07 e 08.

${ }^{12}$ Interessante perceber que, no limiar do século $\mathrm{XX}$, já existia um centro congregando indústrias nacionalmente, sem que necessariamente existissem bases locais. Como aponta Bernardo (1982): "De fato, em 1904 os empresários industriais criaram o Centro Industrial do Brasil com o objetivo de promover o desenvolvimento e a prosperidade dos diversos ramos da indústria, concorrendo quando possível, para a formação nos Estados, de associações congêneres de maneira a estabelecer com segurança a federação dos interesses industriais no Brasil" (BERNARDO, 1982 , p. 13).

13 É o que afirma Costa (1986), comentando esse decreto: "Os sindicatos de empregadores poderiam constituir-se por profissões ou atividades exercidas numa mesma localidade, num mesmo ou em vários Estados ou em todo o País. Já no caso dos empregados, os seus sindicatos deveriam ser apenas locais. Somente em situações especiais, atendendo às condições peculiares a determinadas profissões, o Ministério do Trabalho, Indústria e Comércio fixava, aos sindicatos respectivos, uma base territorial mais extensa. Neste caso, portanto, fica patente a intenção de limitar, em termos territoriais, a organização sindical dos trabalhadores, reduzindo a possibilidade da formação de um sindicato mais forte, com um poder de barganha maior" (COSTA, 1986, p. 36).

${ }^{14}$ Como vimos no caso de um sindicato do Pará em aliança com o sindicato do Rio.

\section{Referências Bibliográficas}

BERNARDO, Antonio Carlos. Tutela e Autonomia Sindical Brasil: 1930-1945. São Paulo: T.A.Queiroz Ltda, 1982.

CARVALHAL, Marcelo Dornellis. A Dimensão Territorializante da Qualificação Profissional em São Paulo: A Ação dos Sindicatos. Presidente Prudente: Tese de Doutorado, UNESP-PP, 2004.

COSTA, Rogério Haesbaert. O Mito da Desterritorialização: Do fim dos Territórios à Multiterritorialidade. Rio de Janeiro: Bertrand Brasil, 2004.

COSTA, Sérgio Amad. Estado e Controle Sindical no Brasil. São Paulo: T.A. Queiroz, Editor, 1986.

COSTA, Wanderley M. O Estado e as Políticas Territoriais no Brasil. São Paulo: Contexto/ EDUSP, 1988.
- Geografia Política e Geopolítica Discursos sobre o território e o poder. São Paulo: Editora Hucitec/EDUSP, 1992.

DEAN, Warren. A Industrialização de São Paulo. São Paulo: Editora Difel, 1971.

DIAS, Everardo. História das Lutas Sociais no Brasil. São Paulo: Alfa-ômega, 1977.

LOPREATO, Christina R. O Espírito da Revolta: A Greve Geral Anarquista de 1917. São Paulo: Annablume, 2000.

MARAM, Leslie Sheldon. Anarquistas Imigrantes e o Movimento Operário 1890/1920. São Paulo: Editora Paz e Terra, 1975.

MARTINS, José de Souza. O Cativeiro da Terra. São Paulo: Editora Hucitec, 1986.

MELLO, João Manuel C. O Capitalismo Tardio. São Paulo: Editora Brasiliense, 1982. 
MORAES, Antonio Carlos Robert. Ideologias Geográficas - Espaço, Cultura e Política no Brasil. São Paulo: Editora Hucitec/Annablume, 1988.

Geografia, Capitalismo e Meio Ambiente. 2000. São Paulo: Tese de Livre Docência, FFLCHUSP, São Paulo.

. Geografia: Pequena História Crítica. São Paulo: Hucitec, 1987.

. Território e História no Brasil. São Paulo: Annablume/Editora Hucitec, 2002.

. Ratzel. São Paulo: Editora Ática, 1990.

. O que é Território? Revista Orientação, Edição Suplementar, Departamento de Geografia, Outubro/1984.

MORAES FILHO, Evaristo de. O Problema do Sindicato Único no Brasil - Seus fundamentos sociológicos. São Paulo: Alfa-Ômega, 1978.

MOREIRA, Ruy. O movimento operário e a questão Cidade-Campo no Brasil - Estudo sobre Sociedade e Espaço. Rio de Janeiro: Vozes, 1985.

PENHA, Eli Alves. A criação do IBGE no contexto da centralização política do Estado Novo. Rio de Janeiro: FIBGE, 1993.
RAFFESTIN, Claude. Por uma Geografia do Poder. São Paulo: Ática, 1993

SIMÃo, Aziz. Sindicato e Estado. São Paulo: Dominus Editora, 1966.

SFERRA, Giuseppina. Anarquismo e Anarcossindicalismo: Editora Ática, 1987.

THOMAZ JR, Antonio. Por trás dos Canaviais: Os nós da cana. 1996. São Paulo: Tese de Doutorado, FFLCH-USP, São Paulo.

VIANNA, Oliveira - Direito do Trabalho e Democracia Social (O Problema da Incorporação do Trabalhador no Estado). Rio de Janeiro: Livraria José Olympo Editora, 1951.

Jornais e Revistas

Boletim da Comissão Executiva do 30 Congresso Operário - 1920

A Voz do Trabalhador - Pará - 1920

A Voz do Trabalhador - Rio de Janeiro - 1913 e 1914

Revista do Trabalho, Anno V, no 10, Outubro de 1937.

Trabalho enviado em outubro de 2009 Trabalho aceito em dezembro de 2009 